\title{
On the Diversified Teaching Management Pattern of the Pharmacology for Undergraduates
}

\author{
Zhao Yuqin, Chen Yin, Sun Kunlai, Wang Bin, Qu Youle \\ School of Food and Pharmacy \\ Zhejiang Ocean University \\ Zhoushan, Zhejiang 316000, China
}

\begin{abstract}
As the modern instructional ideas and concepts are upgrading and the teaching model of pharmacy is changing, classroom education should follow the student-centered concept that is teacher-oriented and emphasizes both knowledge and capacity, as well as the experimental and theoretical teaching. Besides, we should fully arouse students' enthusiasm and initiative, cultivate their ability to analyze and solve problems and become lifelong learners. Adopted the model of "diversified teaching", this article combines some teaching methods, such as case-study, question-answer, inductive, heuristic and interactive learning in exploring the teaching reform of pharmacology. We break through the traditional "spoon-feeding" method[1].Thus, we improve the teaching level and quality in several layers, including its content, method, form and examination.
\end{abstract}

Keywords-pharmacology; diversified teaching method; independent study; teaching reform

\section{INTRODUCTION}

Pharmacology is a course connecting medicine and pharmacy, basic science and clinical medicine, studying the intracorporal process of drugs, pharmacological effect, mechanism, adverse reaction contraindication and etc.. It has close relation with lots of subjects like anatomy, physiology, pathology, biologic chemistry, microbiology and histoembryology. Wide-ranging and highly-theoretical as it is, studying pharmacology takes much time and energy, which increases students' burden. Therefore, traditional instructional way is not ideal. Traditional teaching is simply teaching and being taught: in the class, teachers impart knowledge without students' participation; students only study in the class, which limits their learning time and ways, to a certain degree; thus, it will lead the theoretical teaching to divorce from practice. The student-centered "diversified teaching" stresses that we should fully mobilize their initiative and propose the "diversification" of instructive methods. Methods like case-study, questionanswer, inductive, heuristic and interactive learning should be employed, so as to increase their interest in learning. Therefore, we can achieve the instructional goals, highlight learning points and break through difficulties[2]

\section{InTEGRATING AND UPGRADING TEACHING CONTENT}

No.1 document of Ministry of Education points out that "we must change the situation that lectures accounts for much time and offer more time and space for students to study independently", "we should vigorously advance teaching methods like discussion lecture and case study and cooperative learning, guide undergraduates to learn various academic opinions, discuss and keep an eye on the development of the subject and improve the ability to study and research independently", "work hard to provide excellent and individual service for students' overall development”.

First, we should formulate the syllabus of "diversified teaching” of pharmacology according to specialized training objective of pharmacy and biopharmaceutics and the pharmacological textbook. Under the pretext that teaching content accords with the discipline system, we should apply "diversified teaching" to the teaching reform of pharmacology in majors like pharmacy and biopharmaceutics, use methods like case-study, question-answer, inductive, heuristic and interactive learning for studying and guiding. Instead of single application, these methods should be combined to realize the ideal effects, based on specific content. Teachers should continuously enrich their knowledge and use these ways and concepts optionally and systematically according to students' characteristics. Thus, we can improve our teaching quality and cultivate their innovative and open mind, as well as the ability to find research and solve problems, so as to achieve the goal that students can develop in an all-round way in the learning process.

That also enjoys significant meaning to transform boring theoretical teaching into the discussion lecture, which is the foundation of drug discovery and innovative drug research, as well as enhance their learning initiative, cultivate their scientific mind and research ability and team work spirit[3,4].Therefore, we can achieve the educational reform in universities and colleges that focuses on fostering students' independent learning and innovative ability in practice.

\section{ReForming TeAching Methods}

The teaching goal of pharmacology is to make student digest the mechanism that how medicine interact with human body, expand their thoughts to learn and research new drug and improve their comprehensive quality. We apply the teacher-oriented and student-centered method to realize students' active learning and also proactively use methods like discussion lecture, heuristic and investigative learning with fully appreciation of their principal position in study[5,6].

1. Case-study teaching: in the class, clinic cases and medical events should be combined. Teachers should organize 
students to discuss in groups and come up with solutions and then make comments. One class divides into $4 \sim 5$ groups and each group has about 10 students. In this authentic way, we can mobilize their curiosity and initiative in learning and train their capacity to analyze and solve problems.

2. Question-answer teaching: in the class, teachers should use different ways to raise questions. First, self-questioning. Teachers ask themselves to answer, which can make students pay attention and guide their thoughts; second, teachers come up with a question to stimulate students' thinking and let them answer; third, leaving questions for students to think. This method can grasp students' attention; arouse their initiative and active classroom atmosphere.

3. Inductive learning: as the complex content of pharmacology that covers lots of basic courses and professional discipline, we can generalize, summarize and compare the knowledge to help students understand and memorize, which can make half the work with double results. For example, in terms of the muscarinic receptor blocking drugs, as different drugs have different selectivity, structure and intracorporal process, they have diverse pharmacological features and clinical application. After learning it, students can make a list to summarize, through which they can master it better.

4. Heuristic learning: introducing the ideas and creative experiments conducted by some famous scientists when they broke through major subjects. For instance, Barry Marshall and Robin Warren, winners of the Nobel Prize in Physiology or Medicine in 2005, discovered the Helicobacter pylori and its effect in gastritis and gastric ulcer. This can enlighten students about how to break through traditional thoughts and do scientific research.

5. Interactive discussion: teachers can use several classes to make student choose some drugs from Chinese Pharmacopoeia and master their pharmacological effects, clinical use and adverse reaction, as well as exchange in groups(16 people).Therefore, each student can learn 16 drugs. Then, each group elects a student with typical analyzing methods to make presentation, so they can expand the species and learn methods beyond textbook. Meanwhile, teachers provide the English name of each medicine and comment on their speech. One or two intensive discussion should be organized in one term. And it counts into usual performance.

\section{Flexible Application of Teaching Methods}

1. Multimedia instruction: make full application of projection, slide and flash to arouse their learning interest and enthusiasm.

2. Bilingual education: it should be fully carried out. Adding English annotation to key contents in instructive material including projection, slides and teaching lessons in both Chinese and English.

3. Establish a complete website for pharmacology: we should build and perfect a pharmacological website, which is an assistant platform for students to communicate with teachers. Students can learn by themselves based on their own progress, using the internet to search for related information and network. Besides, online forum and exchanging board is set up, where teachers can raise a series of hot topics relevant to the subject and guide students to communicate. That will help students have a deeper understanding of the course and increase their interest. As for the assignment, online instruction offers more flexible types of questions. Students can submit their assignment online, while teachers modify and mark it and give correct answer.

\section{COMPLETING THE EXAmination}

1. Raising the proportion of usual performance: grades that can reflect students' ability to solve problems independently, including homework, presentation and panel discussion, should be raised up to $40 \%$, while final examination accounts for $60 \%$.It will mobilize them to take an active part in teaching and enhance their ability.

2. Adjusting the content and question types in final examination: we should sharply increase the number of multiple choices that imitate practical situation, which can investigate their understanding of pharmacology and judgment on specific medicine.

3. Increasing the questions about cases: students should do independent analysis based on the given cases, raising problems and giving solutions. It investigates their ability that thinks systemically and uses pharmacological knowledge to handle clinical practice.

4. Raising the essay questions: essay questions should combine with clinical cases and the development of new drugs, which creates space for students. Through designing solutions, they can think independently, instead of rote learning.

\section{CONCLUSION}

Above all, the "diversified teaching model" combines traditional and new teaching pattern, striving for the scientific design and rational arrangement in both content and form. It will cultivate students' innovative ability to analyze and solve problems by themselves. We will work hard to create a multidimensional environment for them, changing their role as passive receivers. In this way, we can give full play to students' learning initiative and mobility, increase their consciousness and ability of self-development, promote the understanding and mastery of theoretical knowledge, foster their capacity for independent innovation, helping them fit better in the developmental pattern of modern medicine

\section{REFERENCES}

[1] Han Hui, Yin Yanyan, Jia Xuemei, etc.. Analysis of PHL “Localization” Model Applied in Preclinical Medicine Teaching[J].China Higher Medical Education, 2010,(11):63-64.

[2] Pigolkin YI, Lomakin YV, Leonova EN. Realization of the modern educational concept for the organization of the teaching and learning activities at the Department of Forensic Medicine of I.M [J]. Sud Med Ekspert, 2017, 60(5): 61-63.

[3] Zhong Zhixian. Ten Trends in the Reforming of Instructive Model in Universities[J].China Higher Education Research, 2007,(1):88-91. 
[4] Yao Tongwei, Zeng Su, Yu Lushan, etc.. Attempt of Diversified Instructive Pattern in Teaching Pharmaceutical Analysis to Cultivate Students' Scientific Research and Innovative Ability[J]. Journal of Pharmaceutical Practice, 2007,25(4):254-262.

[5] Cannon, Robert, Newble, et al. A Handbook for Teachers in Universities and colleges: A guide to improving teaching methods [M]. 4th edition. London: Kogan, 2000: 234.

[6] Sivan A, Wong LR, Woon C, et al. An Implementation of Active Learning and its Effect on the Quality of Student Learning [J].
Innovations in Education and Training International, 2000, 37 (4): 381 389.

[7] Olopade FE, Adaramoye OA, Raji Y, et al. Developing a competency based medical education curriculum for the core basic medical sciences in an African Medical School[J]. Adv Med Educ Pract, 2016(7): 389398. 